\title{
Presencia de bacterias en bombillas para infusiones y en cavidad oral de pacientes con salud periodontal y antecedentes de enfermedad periodontal: análisis exploratorio
}

\author{
Lider Monges ${ }^{1}$, , Diego Defazio ${ }^{(i)}$, Gisselle Martinez ${ }^{(D)}$, * Carlos Miguel \\ Rios-González 1 \\ ${ }^{1}$ Universidad Nacional de Caaguazú, Facultad de Odontología, Cnel. Oviedo, \\ Paraguay
}

Cómo referenciar este artículo/ How to reference this article:
Monges L, Defazio D, Martinez G, Rios-González CM. Presencia de bacterias en bombillas para infusiones $y$ en cavidad oral de pacientes con salud periodontal y antecedentes de enfermedad periodontal: análisis exploratorio. Mem. Inst. Investig. Cienc. Salud. 2021; 19(3): 54-60

\section{RE S U M E N}

La retención y sobrevivencia de microorganismos orales (MO) en la bombilla para tomar infusiones representa una posible fuente de contaminación de la boca, principalmente en personas con enfermedades periodontales. El objetivo del trabajo fue identificar la presencia de bacterias en bombillas para infusiones y en cavidad oral de pacientes con salud periodontal y antecedentes de enfermedad periodontal. Este fue un estudio observacional, descriptivo de corte transversal con componente analítico. Los participantes del estudio se agruparon en G1 (pacientes con salud periodontal, bombillas estériles para infusiones, con oxido etileno para su uso por 30 días) y G2 (pacientes con antecedente de enfermedad periodontal, bombillas estériles para infusión, con oxido etileno para su uso por 30 días). Participaron del estudio 50 pacientes. En los pacientes sanos (Grupo1) el promedio de Unidades Formadoras de Colonias (UFC) fue de $676 \pm 226$, mientras que en los pacientes con enfermedad periodontal (Grupo 2) el promedio de UFC fue de $817 \pm 345$. En los pacientes sanos (Grupo1) el promedio de MO fue de $668 \pm 165$, mientras que en los pacientes con enfermedad periodontal (Grupo 2) el promedio de MO fue de $774 \pm 156$. Se evidencia la presencia de microorganismos en bombillas para infusiones y en cavidad oral de pacientes con salud periodontal y antecedentes de enfermedad periodontal. El recuento de UFC presentes en la cavidad oral de los pacientes con salud periodontal y antecedentes de enfermedad periodontal fue similar.

Palabras clave: Bacterias, boca, Odontología en Salud Pública.

\section{Presence of bacteria in infusion bombillas and in the oral cavity of patients with periodontal health and a history of periodontal disease: exploratory analysis.}

\begin{abstract}
A B S T R A C T
The retention and survival of oral microorganisms (OM) in the bombillas to take infusions represents a possible source of contamination of the mouth, mainly in people with periodontal diseases. The objective was to identify the presence of bacteria in infusion bombillas and in the oral cavity of patients with periodontal health and a history of periodontal disease. This was an observational, descriptive, cross-sectional
\end{abstract}


study with analytical component. Study participants were grouped into G1 (patients with periodontal health, sterile infusion bulbs, with ethylene oxide for use for 30 days) and G2 (patients with a history of periodontal disease, sterile infusion bulbs, with ethylene oxide for use for 30 days). Fifty patients participated in the study. In healthy patients (Group1) the mean CFU was $676 \pm 226$, while in patients with periodontal disease (Group 2) the mean of Colony Forming Units (CFU) was $817 \pm 345$. In healthy patients (Group1) the mean OM It was $668 \pm 165$, while in patients with periodontal disease (Group 2) the mean OM was $774 \pm 156$. The presence of microorganisms is evidenced in bombillas for infusions and in the oral cavity of patients with periodontal health and a history of periodontal disease. The count of CFU present in the oral cavity of patients with periodontal health and a history of periodontal disease was similar.

Keywords: Bacteria, mouth, Public Health Dentistry.

\section{INTRODUCCIÓN}

Existe evidencia científica de que la transmisión de microorganismos de la boca puede ocurrir a través de la saliva ${ }^{(1)}$. La translocación de especies cariogénicas y periodonto- patógenas puede ser producida y emitida por objetos llevados a la boca, como la bombilla ${ }^{(2)}$.

La retención y sobrevivencia de microorganismos orales en la bombilla representa una posible fuente de contaminación de la boca, principalmente en las personas con enfermedades periodontales que se caracteriza por la aparición de bolsas periodontales que contienen múltiples bacterias patógenas que afectan el soporte dentario, ocasionando la movilidad de la pieza dental y consecuente pérdida de esta, si el paciente no recibe un tratamiento adecuado a tiempo ${ }^{(3,4)}$. El uso frecuente de la misma bombilla y el compartir con diferentes personas, producen incremento de microorganismos en ella, y una recontaminación oral que pueden causar infecciones orales $^{(1,2)}$.

De esta forma, se logrará conocer como objetivo la translocación y el recuento de microorganismos hallados en la bombilla de mate y tereré y a la cavidad oral de pacientes con salud periodontal y antecedentes de enfermedad periodontal ${ }^{(5)}$. Jugando un rol importante como vehículo de propagación de enfermedades locales y sistémicas ${ }^{(6)}$.

En la actualidad, las personas de diversos países como Paraguay, Argentina, Brasil y Uruguay adoptan el hábito común y diario del consumo de mate y terere, siendo compartidas entre parejas, hijos, hermanos, tíos o amigos, sin conocer la salud bucal de ellos, por sobre todo muy poca conciencia pública del uso personal y la correcta higienización de la misma, con el afán de prevenir la translocación de diversas enfermedades criogénicas y periodonto- patógenas a través de la bombilla teniendo una salud bucal desfavorable ${ }^{(7-9)}$.

En los últimos tiempos, se ha dado una importancia y realce a las medidas de prevención, higiene, cuidado de la salud bucal y entre otros métodos para prevenir posibles transmisiones de microorganismos que pueden causar algún tipo de enfermedad o malestar ${ }^{(8)}$.

Las personas necesitan visitar periódicamente a un profesional odontólogo para su control y prevención de posibles enfermedades periodontales, también el cuidado, la limpieza profunda y desinfección permanente de las bombillas que introduce en la boca, y por sobre todo la precaución de con quien compartir la bombilla del mate y terere, si de alguna manera esto no sucede la persona corre el riesgo de contraer microorganismos patógenos que dependiendo de la naturaleza se puede encontrar diversos tipos ${ }^{(10)}$.

Por todo lo anterior se planteó como objetivo, identificar la presencia de bacterias en bombillas para Infusiones y en cavidad oral de pacientes con salud periodontal y antecedentes de enfermedad periodontal.

\section{METODOLOGÍA}

Se realizó un estudio observacional, descriptivo de corte transversal con componente analítico con muestreo no probabilístico por conveniencia. La población estuvo compuesta por 50 pacientes de ambos sexos, de 18 a 60 años con salud 
periodontal y con antecedentes de enfermedad periodontal, que asistieron a la Clínica 1, de la Facultad de Odontología de la Universidad Nacional de Caaguazú, en los meses de agosto a noviembre del año 2019, que accedieron a participar del estudio firmando un consentimiento informado.

Se seleccionaron 25 pacientes que contaban con salud periodontal y 25 pacientes con antecedentes de enfermedad periodontal para el estudio a través del periodontograma.

Se reclutaron pacientes que cumplían con los criterios de inclusión, quienes recibieron informaciones respecto al procedimiento que se llevaría a cabo. Los participantes del estudio se agruparon en G1 (pacientes con salud periodontal, bombillas estériles para infusiones, con oxido etileno para su uso por 30 días) y G2 (pacientes con antecedente de enfermedad periodontal, bombillas estériles para infusión, con oxido etileno para su uso por 30 días).

Una vez que fueron reclutados los sujetos de estudio, se procedió a las siguientes fases:

Primera fase: Se realizó una profilaxis bucal y volvieron a ser citados a los 15 días.

Segunda fase: A los 15 días los pacientes volvieron, se seleccionaron los grupos, luego se estableció el estado del periodonto, a través de la ficha clínica y el periodontograma, donde se valoró la profundidad de sondaje, nivel de inserción, índice de sangrado (índice gingival de Loe), índice de higiene oral simplificado (IHOS), el índice de placa a través del Índice de O'leary y se aplicó un cuestionario a los pacientes de ambos grupos sobre el conocimiento de higiene oral y método de desinfección de su bombilla de infusiones.

Así también se realizó hisopado de la placa bacteriana del paciente, en ambos grupos, este valor se evaluó en el día 0 . Se realizó con la cucharita de black del primer molar superior o inferior, derecho o izquierdo, que no tenían caries ni restauraciones en la zona a extraer. La toma de muestra se extrajo a nivel cervical y oclusal. Las muestras se conservaron en tubos de ensayo en solución de agua peptonada, que fueron trasladados al laboratorio bacteriológico para su siembra, cultivo y observación de los resultados en la placa petrifil para bacterias aerobias. Los valores se detallaron en la ficha microbiológica.

El paciente recibió sus bombillas de infusiones, y volvió a ser citado a los 30 días, pidiéndole que utilice su bombilla como lo venía haciendo actualmente y que traiga sus bombillas para posterior estudio.

Tercera Fase: A los 30 días se procedió a recoger y trasladar las bombillas de ambos grupos al laboratorio en bolsas estériles con solución de agua peptonada para su siembra, cultivo y observación de los resultados en la Placas $3 \mathrm{M}^{\mathrm{TM}}$ Petrifilm ${ }^{\mathrm{TM}}$ para bacterias aerobias.

Luego, los pacientes fueron beneficiados con enseñanza de higiene bucal y desinfección de bombillas de infusiones a través de una charla educativa

El instrumento que se utilizó para llegar a los valores periodontales como la profundidad al sondaje del surco gingival y el índice de hemorragia gingival fue la sonda periodontal de la Universidad Carolina del Norte de la marca Hu-Friedy, que determino la población de estudio en salud periodontal y con antecedentes de enfermedad periodontal.

Para la realización del índice de placa de O'Leary, fue necesario aplicar previamente sobre todas las superficies dentarias por 10 segundos un revelador de placa en su presentación liquida con ayuda de una pinza para algodón e hisopos de algodón; y posterior a un buche con agua, se observaron las superficies teñidas por presencia de placa, las cuales fueron registradas en el periodontograma.

Para el llenado de la placa se utilizaron cucharas de black que luego se colocó en los tubos embebidos en la solución de agua peptonada. Luego para la evaluación microbiológica se utilizó las placas $3 \mathrm{M}^{\mathrm{TM}}$ Petrifilm ${ }^{\mathrm{TM}}$ estériles desechables para bacterias aerobias, agua destilada y ansas estériles.

Para describir las técnicas de higiene bucal y los métodos de higienización de las bombillas para infusiones, se aplicó un cuestionario de 10 preguntas generales, 5 preguntas son acerca de las técnicas de higiene bucal, y 5 preguntas sobre los 
métodos de higienización de las bombillas. Ambos fueron determinados a través de una escala: BUENO: 4 o 5 preguntas correctas, REGULAR: 3 preguntas correctas y MALA: 1 o 2 preguntas correctas.

Se solicitó autorización de la Dirección de Clínicas, y la Dirección académica de la Facultad de Odontología. Así también se solicitó la aprobación del protocolo de Investigación al Comité de Ética de la Facultad de Odontología de Universidad Nacional de Caaguazú para la realización del estudio. En todo momento fueron respetados los principios de respeto a las personas, beneficencias/no maleficiencia, justicia e igualdad.

Los datos proveídos por los instrumentos fueron cargados inicialmente en una planilla de Microsoft Office Excel, posteriormente fueron exportados para el análisis en el paquete Stata 14.0. Fueron realizados análisis descriptivo y comparación de grupos mediante prueba $t$, donde se consideró una $p<0,05$ como significativa.

\section{RESULTADOS}

El 77,55\% (39) de la población de estudio consumía hierbas en su tereré o mate.

En los pacientes sanos (Grupo 1) el promedio de UFC fue de $676 \pm 226$, mientras que en los pacientes con antecedentes de enfermedad periodontal (Grupo 2) el promedio de UFC fue de $817 \pm 345$.

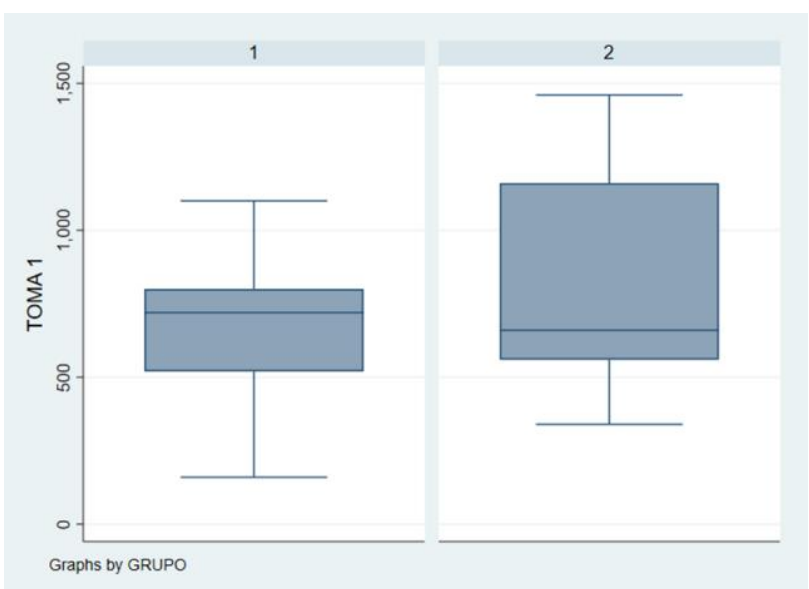

Figura 1: Recuento de Unidades formadoras de Colonias bacterianas presentes en la cavidad oral de los pacientes con salud periodontal y antecedentes de enfermedad periodontal. $\mathrm{n}=50$.

En los pacientes sanos (Grupo 1) el promedio de MO fue de $668 \pm 165$, mientras que en los pacientes con antecedentes de enfermedad periodontal (Grupo 2) el promedio de MO fue de $774 \pm 156$.

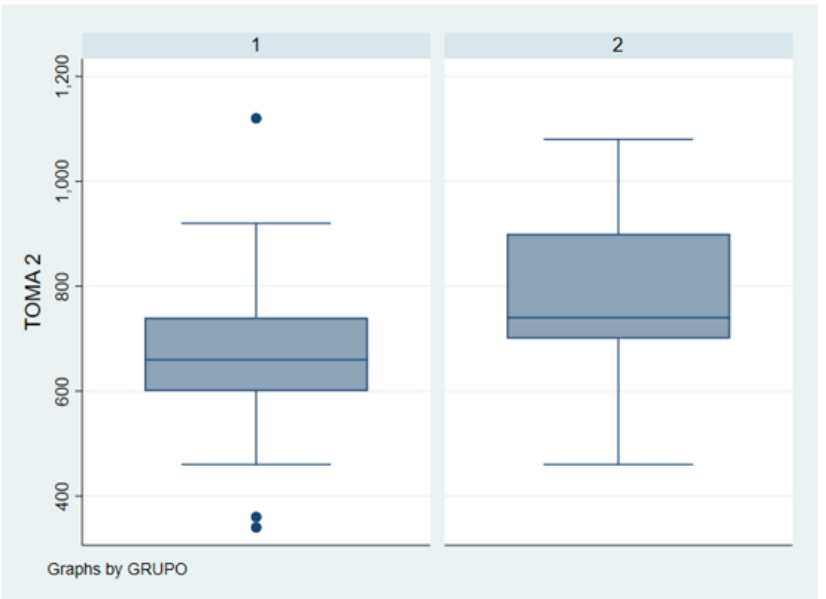

Figura 2: Recuento de microorganismos presentes en las bombillas de infusiones de los pacientes con salud periodontal y antecedentes de enfermedad periodontal. $n=50$. 
Existió una relación directa entre el método de higienización de las bombillas de infusiones y el recuento de colonias bacterianas presentes en la boca, mientras peor sea el método de higienización de las bombillas de infusiones mayor será la cantidad de colonias bacterianas presentes en la cavidad bucal y mayor será el riesgo de transferir microorganismos por la bombilla (Tabla 1).

Tabla 1: Distribución de la localización, calidad de higiene de bombillas de infusiones y calidad de técnica de higiene.

\begin{tabular}{lccc}
\hline & $\begin{array}{c}\text { Salud periodontal } \\
\text { (UFC) }\end{array}$ & $\begin{array}{c}\text { Enfermedad } \\
\text { periodontal (UFC) }\end{array}$ & p \\
\hline Localización & $\mathrm{X} \pm \mathrm{SD}$ & $\mathrm{x} \pm \mathrm{SD}$ & \\
$\begin{array}{l}\text { Cavidad oral } \\
\text { Bombilla }\end{array}$ & $676 \pm 45$ & $817 \pm 69$ & 0.009 \\
Calidad de higiene de las bombillas de infusiones & & $774 \pm 31$ & 0.002 \\
\hline Bueno & & \\
Regular & $623 \pm 38$ & $880 \pm 52$ & 0.007 \\
Malo & $702 \pm 50$ & $760 \pm 34$ & 0.3315 \\
Calidad de la técnicas de higiene bucal & & \\
\hline Bueno & $610 \pm 91$ & $624 \pm 43$ & 0.919 \\
Regular & $573 \pm 93$ & $710 \pm 165$ & 0.0049 \\
Mala & $756 \pm 44$ & $905 \pm 94$ & 0.0130 \\
\hline
\end{tabular}

\section{DISCUSIÓN}

El mate/tereré es una bebida clásica de frecuente empleo diario en la mayor parte de la población ${ }^{(11)}$. El consumo de esta bebida podría implicar un riesgo para la salud si estuviera contaminada con cualquier tipo de patógeno. Existen factores ambientales que favorecen la contaminación y la supervivencia de microorganismos sobre distintos tipos de superficies, entre ellos la bombilla ${ }^{(12)}$.

Este es el primer estudio donde se explora la presencia de bacterias en las bombillas de infusión utilizadas para mate o tereré, en la cual recae su relevancia, que si bien la muestra es pequeña, da pie a otras investigaciones con tamaños muestrales mayores para buscar causalidad.

Con el presente trabajo, se ha podido evidenciar que existe una cantidad de microorganismos semejantes presentes en las bombillas de infusiones y en la cavidad oral de dos grupos (pacientes con salud periodontal y antecedentes de enfermedad periodontal), también que existe una translocación de microorganismos de la boca a la bombilla. Así también que el conocimiento sobre el método de higienización de las bombillas de infusiones tiene relación en un $72 \%$ de microorganismos presentes en las bombillas de infusiones, y un $56 \%$ de colonias bacterianas presentes en la cavidad oral, existiendo así una relación con los hábitos de higiene bucal de ambos grupos de pacientes. Abarca Pazmiño $A B$ et $a^{(13)}$, realizaron un estudio donde encontraron la presencia de crecimiento de microorganismos en cepillos dentales sin buena higiene, de ahí la importancia de la buena higiene de los objetos que serán introducidos a la boca.

Imarenezor et al. ${ }^{(14)}$ destacan que la presencia de malos hábitos de higiene dental contribuye a un aumento en el UFC a nivel de boca, incluso se puede identificar la presencia de patógenos de importante relevancia, tales como E. coli, Campylobacter sp. y Streptococcus sanguinis ${ }^{(15,16)}$. Si bien, no se ha podido recuperar información sobre la presencia de bacterias en las bombillas de infusión, diversos autores destacan la presencia de bacterias en la yerba mate, las cuales pueden ser transportadas y permanecer en las bombillas de infusión, de acuerdo al tiempo de supervivencia de las bacterias y otros microorganismos a la superficie ${ }^{(17-21)}$.

Las limitaciones del estudio se centran en la cantidad del tamaño de la muestra, así como en el muestreo, puesto que al ser un muestro no probabilístico no presenta validez externa, por lo que se sugiere realizar estudios con una muestra mayor para 
alcanzar resultados con menor variabilidad, además de tipificar los tipos de bacterias encontradas.

A modo de conclusión se evidencia la presencia de microorganismos en bombillas para infusiones y en cavidad oral de pacientes con salud periodontal y antecedentes de enfermedad periodontal. El recuento de unidades formadoras de colonias bacterianas presentes en la cavidad oral de los pacientes con salud periodontal y antecedentes de enfermedad periodontal fue similar, encontrándose resultados estadísticamente semejantes.

Financiamiento: Autofinanciado.

Conflicto de Interés: Los autores no declaran conflictos de intereses.

\section{Contribución de autores}

ML y DD: investigación documental, análisis e interpretación de datos, redacción del manuscrito.

GM y CMRG: asesoría, revisión crítica del manuscrito, aprobación de su versión final. Todos los autores han contribuido en la elaboración del presente manuscrito.

\section{REFERENCIAS BIBLIOGRÁFICAS}

1. Costa EM, Silva S, Veiga M, Tavaria FK, Pintado MM. A review of chitosan's effect on oral biofilms: perspectives from the tube to the mouth. Journal of Oral Biosciences 2017; 59 (4): 205-10. https://doi.org/10.1016/j.job.2017.07.0 $\underline{01}$

2. Fierro-Monti C, Aguayo-Saldías C, LilloCliment F, Riveros-Figueroa F. Rol de los Probióticos como Bacterioterapia en Odontología. Revisión de la Literatura. Odontoestomatología [Internet]. 2017 Dic [citado 2021 Ago 20]; 19 (30): 413. Disponible en:

http://www.scielo.edu.uy/scielo.php?scr ipt $=$ sci arttext\&pid $=$ S1688-

93392017000300004\&lng=es. http://dx.doi.org/10.22592/ode2017n3 0a2

3. Taboada-Aranza O, Cerón Argüelles J, Rodríguez Hernández $A$. Frecuencia y distribución de enfermedades periodontales asociadas a placa bacteriana en pacientes que acuden a una clínica universitaria. Rev ADM. 2018; 75 (3): 147-52. Disponible en: https://www.medigraphic.com/cgibin/new/resumen.cgi?IDARTICULO $=803$ $\underline{55}$

4. Chimenos-Küstner $E$, Giovannoni $M L$, Schemel-Suárez M. Disbiosis como factor determinante de enfermedad oral y sistémica: importancia del microbioma. Medicina Clínica. 2018; 149 (7): 305-9. Doi: https://doi.org/10.1016/j.medcle.2017. 05.023

5. Alvarez MA. Pharmacological properties of native plants from Argentina. Luxemburgo: Springer International Publishing; 2019. Disponible en: https://link.springer.com/book/10.1007 1978-3-030-20198-2

6. Pairazamán-García J, Ríos-Caro T. Efecto inhibitorio in vitro del extracto etanólico de Stevia rebaudiana sobre los factores de virulencia cariogénicos de Streptococcus mutans ATCC 25175. Agroindustrial Science. 2020; 10 (1): 95-102.

https://revistas.unitru.edu.pe/index.ph $\mathrm{p} /$ agroindscience/article/view/2864/325 1

7. Iommi C. Yerba Mate, Tereré or Chimarrão? Different Countries, Historical Legacy, and Similar Preparations. In Chemistry and Safety of South American Yerba Mate Teas. 2020: 63-7.

https://link.springer.com/chapter/10.10 07/978-3-030-69614-6_6.

8. Soria $N$, Ramos $P$, Viveros $G$, Estigarribia $G$, Ríos $P$, Ortíz $A$. Etnobotánica y uso de plantas medicinales en unidades familiares de salud de Caaguazú, Paraguay. Caldasia 2020; 42(2): 263-77. https://doi.org/10.15446/caldasia.v42n 2.76907

9. Pavanelli MF, Santos IC. Coliformes totais e Termotolerantes em Ervas de Tereré Nacionais E Importadas. SaBiosRevista De Saúde E Biologia. 2020; 15(2): 6-10.

10. Sleiman Y, Gayozo E, Torres E. El Efecto antibacteriano del extracto etanólico de Chenopodium pilcomayense Aellen. Steviana. 2017; 9(1): 3-15. https://revistascientificas.una.py/index. php/stevia/article/view/1205

11. Petroselli G, Parapugna TL, Lagorio MG, Erra-Balsells R. MALDI-and LDI-MS 
saponin fingerprint of leaves and stick components of commercial yerba mate (Ilex paraguariensis). Journal of Mass Spectrometry 2019; 54(2): 195-203. https://doi.org/10.1002/jms.4324

12. Chimenos-Küstner $\mathrm{E}$, Schemel-Suárez M, Robledo-Ramos C. Xenobióticos: implicación en enfermedad oral y sistémica. Piel. Formación continuada en dermatología. 2018; 33 (8): 507512.

13. Abarca Pazmiño AB, Guerrero Vaca DI, León Velastegui MA, Escobar Zabala OD. Clorhexidina al $0,12 \%$ y ácido acético al 5\% como desinfectantes de cepillos dentales. Revista Eugenio Espejo 2020; 14(1): 53-64. https://doi.org/10.37135/ee.04.08.08

14. Imarenezor EP, Brown SC, Ebuara FU, Sani S. Identification and antibiogram of bacteria from used toothbrushes by students of Federal University Wukari, North East, Nigeria. FUW Trends in Sci Technol J 2019; 4: 657-9.

https://www.researchgate.net/publicati on/340511020 IDENTIFICATION AND ANTIBIOGRAM OF BACTERIA FROM U SED TOOTHBRUSHES BY STUDENTS OF FEDERAL UNIVERSITY WUKARI $\mathrm{N}$ ORTH EAST NIGERIA

15. Arrúa JM, Franco G, Ibarra PA, Arias TR. Evaluación preliminar del efecto antimicrobiano y toxicidad aguda del extracto etanólico bruto de Luehea divaricata (Ka'a ovetĩ). Rev. Invest. y Est.-UNA 2020; 11(2): 78-86. https://revistascientificas.una.py/index. $\mathrm{php} / \mathrm{rdgic} /$ article/view/977

16. Solis G, Pesaressi E, Mormontoy W. Tendencia y factores asociados a la frecuencia de cepillado dental en menores de doce años, Perú 20132018. Rev. perú. med. exp. salud publica 2019; 36 (4): 562-72. http://dx.doi.org/10.17843/rpmesp.201 $\underline{9.364 .4888}$
17. Viteri-García A, Parise-Vasco JM, Cabrera-Dávila MJ, Zambrano-Bonilla MC, Ordonez-Romero I, Maridueña-León MG, Armas-Vega A, et al. Prevalencia e incidencia de caries dental y efecto del cepillado dental acompañado de barniz de flúor en escolares de Islas Galápagos, Ecuador: protocolo del estudio EESO-Gal. Medwave. 2020; 20(06): e7974.

https://doi.org/10.5867/medwave. 2020 .06 .7974

18. Richer Y, Silva A, Garlisi D, Diaz SR. Calidad microbiológica del macerado de plantas medicinales utilizadas para el consumo de tereré en Asunción y Gran Asunción del Paraguay. Rev. cient. cienc. salud 2019; 1(2): 44-50. https://doi.org/10.53732/rccsalud/01.0 2.2019.44

19. Delgado Vaca KN, Riofrio Cordero HA. Propuesta de tratamiento para los Lodos generados en la PTAR Tereré de la Ciudad Tena mediante la caracterización físico químico y microbiológica de los mismos. (Bachelor's thesis, Universidad Estatal Amazónica). Pastaza - Ecuado. 2020. https://repositorio.uea.edu.ec/handle/1 23456789/820

20. Chamorro G, Ibarz-Pavon AB, Kawabata $A$, León $M E$, Orrego $V$, Nagai $M$, Gabastou JM. Carriage of Neisseria meningitidis and other Neisseria species among children and young adults in Paraguay. J Med Microbiol. 2019; 68(12): 1793-1801.

https://doi.org/10.1099/jmm.0.001097

21. Soejarto DD, Addo EM, Kinghorn AD. Highly sweet compounds of plant origin: From ethnobotanical observations to wide utilization. Journal of ethnopharmacology. 2019: 243: 112056. https://doi.org/10.1016/j.jep.2019.112 $\underline{056}$ 